\title{
SOLVATOCHROMISM STUDIES ON UV SPECTRA OF 4,5-DISUBSTITUTED-1,2,4-TRIAZOLINE-3-THIONES
}

\author{
Vesna B. Dimova ${ }^{1 *}$, Nada U. Perišić-Janjić ${ }^{2}$ \\ ${ }^{1}$ Faculty of Technology and Metallurgy, Ss.Cyril and Methodius University, \\ Ruger Bošković 16, P.O. Box 580, MK-1001 Skopje, Republic of Macedonia \\ ${ }^{2}$ Department of Chemistry, Faculty of Sciences, University of Novi Sad, \\ Trg Dositeja Obradovića 3, 21000 Novi Sad, Serbia \\ vdimova@tmf.ukim.edu.mk
}

The influence of a series of organic solvents on the UV spectra of investigated 1,2,4-triazoles, was studied by implementing solvatochromic theory. As a part of our efforts to interpret the effects of solvent polarity and hydrogen bonding on the absorption spectra of previously synthesized 1,2,4-triazoline3-thiones, the study design was based on the linear solvation energy relationship (LSER) concept using Kamlet-Taft solvatochromic parameters: $\pi^{*}, \alpha$ and $\beta$. Accordingly, by dividing the solvents into two groups (protic and aprotic) it was ascertained that improved solvatochromic three-correlation models for the group of protic solvents were obtained. The results show that the solvent effect on UV absorption spectra of investigated thiones was very complex and strongly dependent on the nature of the substituent in positions 4 and 5 in 1,2,4-triazole moiety. Moreover, the statistical evaluation of the models (R, SD, $\mathrm{Q}^{2}$ and PRESS/ SSY) showed satisfactory values.

Keywords: 1,2,4-triazoline-3-thiones; UV spectra; solvent effects; LSER concept

\section{ИСПИТУВАҢЕ НА СОЛВАТОХРОМИЗМОТ КАЈ УЛТРАВИОЛЕТОВИТЕ СПЕКТРИ НА 4,5-ДИСУПСТИТУИРАНИ-1,2,4-ТРИАЗОЛИН-3-ТИОНИ}

Со примена на солватохромната теорија е испитано влијанието на серија органски растворувачи на UV-спектрите на 1,2,4-триазоли. Ефектите на поларноста на растворувачите и создавањето на водородни врски се проучувани со примена на методот на линеарна корелација на солватационите ефекти (концептот LSER), со користење на Kamlet-Taft-овите солватохромни параметри: $\pi^{*}, \alpha$ и $\beta$. Со поделба на растворувачите во две групи (протични и апротични) се добиени подобрени три корелациони модели. Според резултатите, влијанието на растворувачите е комплексно и силно зависно од карактерот на супституентите присутни во положбите 4 и 5 во 1,2,4-триазолната единица. За презентираните модели се добиени задоволителни статистички вредности за параметрите R, SD, $\mathrm{Q}^{2}$ и $\mathrm{PRESS} / \mathrm{SSY}$,

Клучни зборови: 1,2,4-триазолин-3-тиони; UVспектри; влијание на растворувачи; концепт LSER. 


\section{INTRODUCTION}

The significance and interest of biological active compounds with 5 member heterocyclic rings in their structure, such as 1,2,4-triazole ring, have been increasing over the past years. Spurred by this facts, we synthesized and investigated some new 1,2,4-triazole derivatives during the last ten years [1-8]. It is also known that 1,2,4-triazole nucleus is associated with diverse biological activities such as: analgetic, antiasthmatic, diuretic, antihypertensive, antibacterial, antifungal and antiinflammatory properties [9-13].

It is perhaps obvious that consideration of physical properties such as melting point, boiling point, viscosity and solvent polarity are essential when choosing a solvent for a particular application. For a chemical reaction, it is also vital that one has some understanding of how well the substrates, reagents and products will dissolve. This is governed by a number of factors, which together make up the character of the solvent. This general character of the solvent is frequently termed polarity but, unfortunately, the concept of solvent polarity is not a simple one. Solvent polarity might best be defined as the solvation power of a solvent, and depends on the interplay of electrostatic, inductive, dispersive, charge-transfer and H-bonding forces.

Solvent polarity is among the most widely used concepts in chemistry [14-24]. Most solvent polarity scales are empirical and different empirical solvent polarity scales have been shown to correlate well with each other, pointing to the existence of an underlying common feature. Around 35 solvent scales are known. However, only about ten of them have found wider application in the correlation analysis of solvent effects, i.e. $\alpha, \beta, \pi^{*}$, , $E_{T}^{N}, S P P, S A$ and $S B$. Empirical solvent polarity scales based on spectroscopic measurements usually employ changes in the UV absorption maximum of an indicator in different solvents (solvatochromism) [14-17, 22-23]. Multiple intermolecular solute/solvent interactions can be described by the linear solvation energy relationship (LSER) concept, developed by Kamlet-Taft [14-17], as one of the most ambitious and suc- cessful, quantitative treatments of solvent effects by means of a multiparameter equation.

Although, Kamlet-Taft approach first was used for determination the solvatochromic behaviour of the dyes [14], it was interesting to apply the same approach for biological active heterocyclic compound as are investigated triazoline-3thiones.

In this paper we also wanted to delineate the different interaction of protic and aprotic solvents with previously synthesized 4,5-disubstituted-1,2,4-triazoline-3-thiones (T3T). The obtained knowledge is important for their further applications and also for their limitation. To achieve this task, their UV spectra were recorded in eleven solvents and the position of electronic absorption bands was determined. The effects of solvent polarity and hydrogen bonding on the absorption spectra were interpreted by means of LSER.

The overall goal of this paper is to initiate preliminary investigations of solvation of biological active T3T which is closely connected with the stabilizing and destabilizing effects of solvent on triazoline-3-thione structure. Therefore, the study of solvation processes of T3T in various organic media is important to elucidate the connection between their chemical ability and biological activity.

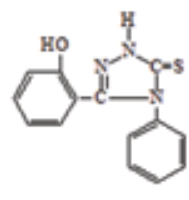

(T1)

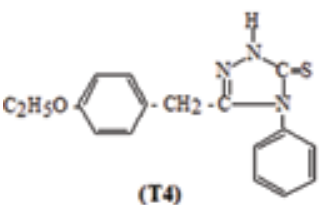

(T4)

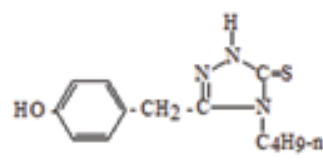

(T7)

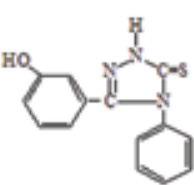

(T2)

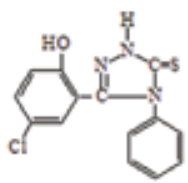

(T3)
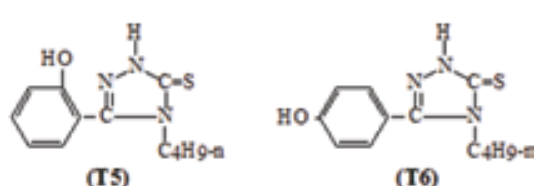

(T6)

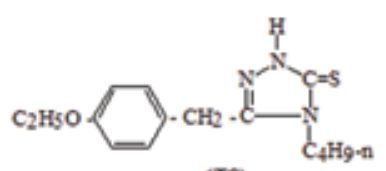

(T8)

Fig. 1. 4,5-Disubstituted-1,2,4-triazoline-3-thiones (T3T) 


\section{EXPERIMENTAL}

\subsection{Materials}

The complete synthesis of the triazoline3-thione derivatives (T3T) (Figure 1), has been reported elsewhere [1]. The structure of the novel thiones were confirmed by: $\mathrm{IR}, 1 \mathrm{H}$ and ${ }^{13} \mathrm{C}$ NMR, UV and quantitative elemental analyses. The spectral data support the proposed structure. While it is possible to consider that T3T may exist in thione-thiol tautomeric forms our chemical and spectral investigations showed that the thion structure dominates.

The ${ }^{1} \mathrm{H}$ NMR spectra of T3T in DMSO- $\mathrm{d}_{6}$ exhibited: the NH signals ( $\mathrm{NH}$ group of the thiazoline ring) as singlet or broad peaks between 13.55 and $14.10 \mathrm{ppm}$ supported the thione structure [1, $10,12]$; the signals associated with other functional groups appeared in the expected regions.
The IR spectra in $\mathrm{KBr}$ disk showed multiple combination of $\mathrm{NH}$ bands in the $3380-3300 \mathrm{~cm}^{-1}$ region and showed no absorption bands about $2600-2550 \mathrm{~cm}^{-1}$ which is indicative of the thiol form; the IR absorption due to $\mathrm{C}=\mathrm{S}$ functions in T3T appeared around $1300 \mathrm{~cm}^{-1}$. Their UV spectra (wather) showed two absorption maxima or shoulders at 250-267 and 282-290 nm [1, 12].

\subsection{Solvents used for solvent effect investigation}

Solvents with different characteristics were used for investigation of solvent effect: water, methanol, ethanol, propan-1-ol, butan-1-ol, chloroform, dioxane, N,N-dimethylformamide (DMF), formamide (FA), dimethyl sulfoxide (DMSO) and acetonitrile (Table 1). Pro-analysisgrade solvents were purchased from A. D. Alkaloid (Skopje, Republic of Macedonia) and Merck (Germany).

$\mathrm{T}$ a b l e 1

Solvent parameters taken from Ref. [14]

\begin{tabular}{lccccccc}
\hline \multirow{2}{*}{ Solvent } & \multicolumn{7}{c}{ Solvent parameters $^{a}$} \\
\cline { 2 - 8 } & $\varepsilon$ & $\mu 10^{30} \mathrm{~cm}$ & $n$ & $\mathrm{E}_{\mathrm{T}} \mathrm{N} / \mathrm{E}_{\mathrm{T}} 30$ & $\pi^{*}$ & $\beta$ & $\alpha$ \\
\hline Water & 78.36 & 6.2 & 1.3330 & $1.000 / 63.1$ & 1.09 & 0.18 & 1.17 \\
Methanol & 32.66 & 9.6 & 1.3284 & $0.762 / 55.4$ & 0.60 & 0.60 & 0.93 \\
Ethanol & 24.55 & 5.5 & 1.3614 & $0.654 / 51.9$ & 0.54 & 0.77 & 0.83 \\
Propan-1-ol & 20.45 & 5.5 & 1.3856 & $0.617 / 50.7$ & 0.52 & 0.00 & 0.78 \\
Butan-1-ol & 17.51 & 5.8 & 1.3993 & $0.586 / 49.7$ & 0.47 & 0.88 & 0.79 \\
Chloroform & 4.89 & 3.8 & 1.4460 & $0.259 / 39.1$ & 0.58 & 0.00 & 0.44 \\
Dioxane & 2.21 & 1.5 & 1.4224 & $0.164 / 36.0$ & 0.55 & 0.37 & 0.00 \\
DMF & 36.71 & 12.7 & 1.4305 & $0.386 / 43.2$ & 0.88 & 0.63 & 0.00 \\
FA & 109.5 & 11.2 & 1.4475 & $0.775 / 55.8$ & 0.97 & 0.00 & 0.71 \\
DMSO & 46.45 & 13.5 & 1.4790 & $0.444 / 45.1$ & 1.00 & 0.76 & 0.00 \\
Acetonitrile & 35.94 & 13.0 & 1.3440 & $0.460 / 45.6$ & 0.75 & 0.31 & 0.19 \\
\hline \hline
\end{tabular}

\subsection{Investigation of solvent effect}

Stock solutions of T3T $\left(1 \cdot 10^{-3} \mathrm{~mol} \mathrm{dm}^{-3}\right)$ were prepared by dissolving the required amounts of the substances in absolute ethanol (Alkaloid, Skopje). These solutions were stable for a long time - during two months there were no changes in their absorption spectra. The concentration of the test solutions of the investigated compounds was $1 \cdot 10^{-5} \mathrm{~mol} \mathrm{dm}^{-3}$, and there was prepared by dissolving appropriate amount of stock solutions in appropriate solvent into $10 \mathrm{ml}$ volumetric flask. 


\subsection{LSER concept - Kamlet-Taft approach for investigation of effects of solvent polarity and hydrogen bonding on the absorption spectra}

Multiple intermolecular solute/solvent interactions can be described by the linear solvation energy relationship, concept first described by Kamlet and Taft using eq. (1):

$$
v_{\max }=v_{o}+s \pi^{*}+b \beta+a \alpha
$$

where $\pi^{*}, \beta$ and $\alpha$ are solvatochromic parameters and $s, b$ and $a$ are the solvatochromic coefficients [14]. Solvent parameters: $\pi^{*}, \beta$ and $\alpha$ chosen for investigation of solvent effect are given in Table 1 .

\subsection{Spectrophotometric measurements}

The spectrophotometric measurements, in the region $200-500 \mathrm{~nm}$, where carried out on a Varian Cary 219 spectrophotometer, in a $1 \mathrm{~cm}$ quartz cells, at $25 \pm 1{ }^{\circ} \mathrm{C}$.

\subsection{Correlation evaluation}

The statistical evaluation of the data was performed using ORIGIN 7.0 Professional (OriginLab Corporation, Northampton, USA) and STATISTICA 6 (StaSoft, Inc., Tulsa, USA).

\section{RESULTS AND DISCUSSION}

Modelling of solvent effects is one of the most useful methods to obtain information about the mechanism of all organic reactions which include biologically active compounds. A solvent would provide not only an environment for the reaction to occur but would stabilize the reactants and the transition state species by solvating process. This solvation is due to solvent-solute interactions during which a solvent act either as a nucleophile or an electrophile by donating or accepting electron pairs from the solute. It can also form hydrogen bonds with the specific sites of the solute molecules.

The present study deals with the solvent effect on the absorption spectra of T3T which belongs to group of triazoline-3-thiones. The molecular structure of chosen compounds (T1 - T8) is shown in Figure 1. Absorption spectra of the T3T solution were recorded in different solvents with the aim to probe the effects of various solvents and correlate various absorption parameters (Table 2). For this purpose solvents of different types were selected: protic solvents (also called as hydrogen-bond donating - HBD type solvents) such as water and alcohols (methanol, ethanol, propan1-ol, butan-1-ol) and aprotic solvents (also called non hydrogen-bond donating - non-HBD type of solvents) such as: DMF, FA, DMSO, acetonitrile (dipolar solvent) and chloroform, dioxane (apolar solvent).

\subsection{Solvent effects on the UV absorption spectra of 4,5-disubstituted-1,2,4-triazoline-3-thiones}

(T1-T8)

Electronic absorption spectra of investigated compounds have in aqueous solutions characteristic absorption frequencies $\left(v_{\max }=1 / \lambda_{\max }\right)$ at about $40.00-37.45 \cdot 10^{3} \mathrm{~cm}^{-1}$ and $35.46-34.48 \cdot 10^{3}$ $\mathrm{cm}^{-1}$. In accordance with the reported data [1], absorption frequencies at about $40.00-37.45 \cdot 10^{3}$ $\mathrm{cm}^{-1}$ correspond to the overlapping $n-\pi^{*}$ transition of triazoline-3-thione and $\pi-\pi^{*}$ transition of benzene rings $[1,12]$. The absorption at 35.46$34.48 \cdot 10^{3} \mathrm{~cm}^{-1}$ indicates the presence of a chromophoric $\mathrm{C}=\mathrm{S}$ group $[1,10,12]$. In this study, data for unsubstituted T3T $\left(\mathrm{R}=\mathrm{R}^{\prime}=\mathrm{H}\right)$ is not available, discussion about position and intensity of UV absorption frequencies, were made according position and type of present substituents.

The experimentally obtained UV data confirmed that the position of the absorption maximum depends on the nature of substituents in position 4 and 5 in triazoline 3 -thione moiety. According to the data presented in Table 2, there was an identical trend in the absorption frequencies of investigated T3T. 
Table 2

Ultraviolet absorption frequencies of the investigated $\mathbf{T 3 T}$ in 11 solvents

\begin{tabular}{lcccccccc}
\hline \hline \multirow{2}{*}{ Solvents } & \multicolumn{7}{c}{$v_{\max } \cdot 10^{3}\left[\mathrm{~cm}^{-1}\right]$} \\
\cline { 2 - 9 } & \multicolumn{7}{c}{ Compounds } \\
\cline { 2 - 9 } & $\mathrm{T} 1$ & $\mathrm{~T} 2$ & $\mathrm{~T} 3$ & $\mathrm{~T} 4$ & $\mathrm{~T} 5$ & $\mathrm{~T} 6$ & $\mathrm{~T} 7$ & $\mathrm{~T} 8$ \\
\hline Water & 39.06 & 38.91 & 39.22 & 39.22 & 39.84 & 39.37 & 40.00 & 40.16 \\
Methanol & 38.02 & 38.02 & 38.17 & 38.31 & 39.22 & 38.76 & 39.22 & 39.06 \\
Ethanol & 38.02 & 38.02 & 38.31 & 38.31 & 39.06 & 38.61 & 39.06 & 39.06 \\
Propan-1-ol & 37.88 & 38.02 & 38.17 & 38.17 & 39.06 & 38.61 & 38.91 & 39.06 \\
Butan-1-ol & 37.88 & 37.88 & 38.31 & 38.17 & 38.91 & 38.46 & 38.91 & 39.06 \\
Chloroform & 37.88 & 37.13 & 38.46 & 37.45 & 38.31 & 37.88 & 38.31 & 38.17 \\
Dioxane & 37.88 & 38.17 & 37.88 & 37.59 & 38.31 & 38.17 & 38.17 & 38.17 \\
DMF & 35.97 & 37.04 & 37.04 & 37.04 & 37.13 & 37.17 & 37.17 & 37.31 \\
FA & 38.17 & 38.17 & 38.17 & 38.02 & 38.02 & 38.02 & 38.02 & 38.02 \\
DMSO & 35.71 & 35.71 & 35.81 & 36.90 & 38.17 & 38.02 & 38.02 & 38.02 \\
Acetonitrile & 38.46 & 37.59 & 37.59 & 37.59 & 38.31 & 38.17 & 38.46 & 38.46 \\
\hline \multicolumn{1}{c}{$\Delta v$} & 3.35 & 4.20 & 3.41 & 2.32 & 2.71 & 2.20 & 2.83 & 2.85 \\
\hline \hline
\end{tabular}

The absorption frequencies of the T3T is affected by solvent type and have a maximum shift of $\Delta v=2.32-4.30 \mathrm{~nm}$ for $\mathbf{T} 1-\mathbf{T} 4$ and $\Delta v=2.20$ $-2.85 \mathrm{~nm}$ for $\mathbf{T 5}-\mathbf{T 8}$ for the solvent used in this study.

Thus, this change in spectral position can be used as a probe for various types of interaction between the solute and solvent. The spectral position of T3T in various solvent has revealed interesting results. Replacement of the substituent in position 4 in triazoline-thione ring (phenyl with $n$-butyl group) in all investigated compounds, generally causes hypsochromic shift of the high wavelength absorption maximum, in all solvents. This is in accordance with aromatic structure (high conjugation of electrons in the benzene ring) in the compounds T1-T4.

The slightly higher absorption frequencies maximum of 4- $n$-butyl-1,2,4-triazoline-3-thiones (T5-T8) than those of 4-phenyl-1,2,4-triazole3-thione (T1-T4) in all solvents indicate an even higher energy of electronic transition in the triazoline-3-thione ring in the butyl substituted thiones. Introduction of $-\mathrm{CH}_{2}-$ moiety between triazoline3-thione and benzene ring was followed by insignificantly hypsochromic shift of the absorption maxima, in all solvents (comparing T1, T2, T3 and T4; T6 and T7).
As it is expected, in case of protic solvents, changing the solvent polarity (water to butan-1-ol), batochromic shift for all compounds appears. In the case of aprotic solvents, since the chosen one can be divided into dipolar and apolar, they differently interact with triazole molecule. In all cases, DMSO had shown lowest $v_{\max }$ for 4-phenyl derivatives and DMF for 4- $n$ buthyl triazoles.

An attempt was made for correlation of experimentally obtained $v_{\max }$ values versus dielectric constant values of chosen solvents. A plot of $v_{\max }$ versus the dielectric constant values in protic solvents is shown in Figure 2.

The absorption values were also related to the solvent polarity parameter, namely $E_{\mathrm{T}}(30)$, which also considers other interactions besides those of specific nature. The values of $E_{\mathrm{T}}(30)$ were obtained from the literature for various solvents used in this work and are listed in Table 1 [14]. Figures 3 shows the correlation between the absorption value (in $\mathrm{cm}^{-1}$ ) and $E_{\mathrm{T}}(30)$ for the T3T studied in this work. A linear correlation of absorption energy covering a range of $E_{\mathrm{T}}(30)$ only for protic solvents indicates the presence of specific nature of interactions between the solute and solvents. 


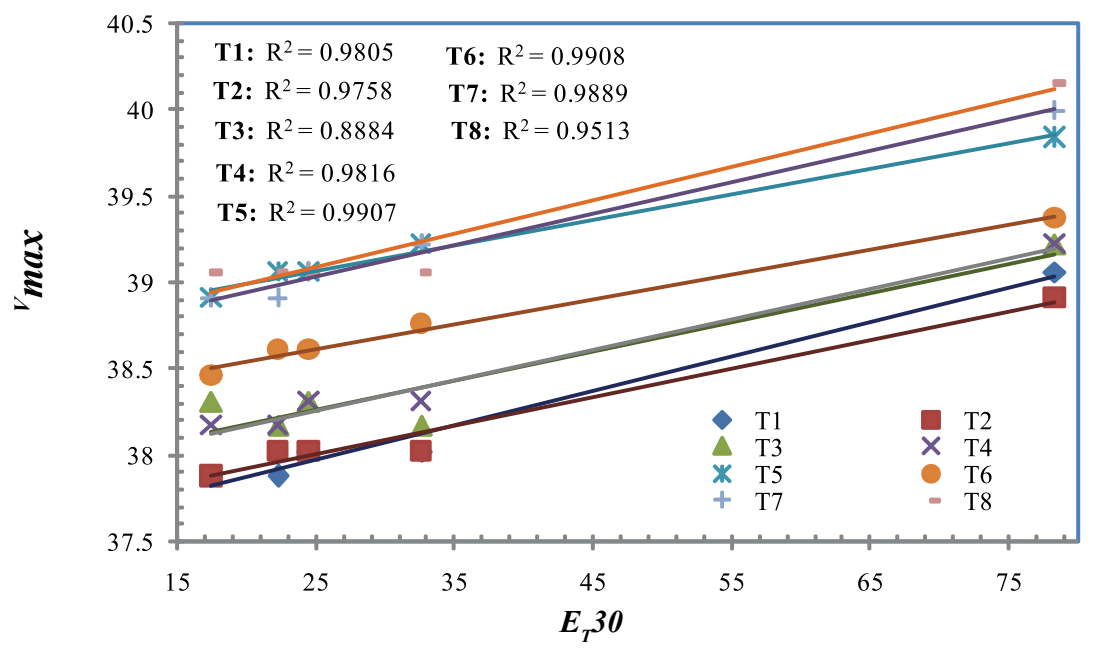

Fig. 2. Plot of absorption frequency (in $\mathrm{cm}^{-1}$ )

of T3T in various solvents versus the $\varepsilon$ values in protic solvents

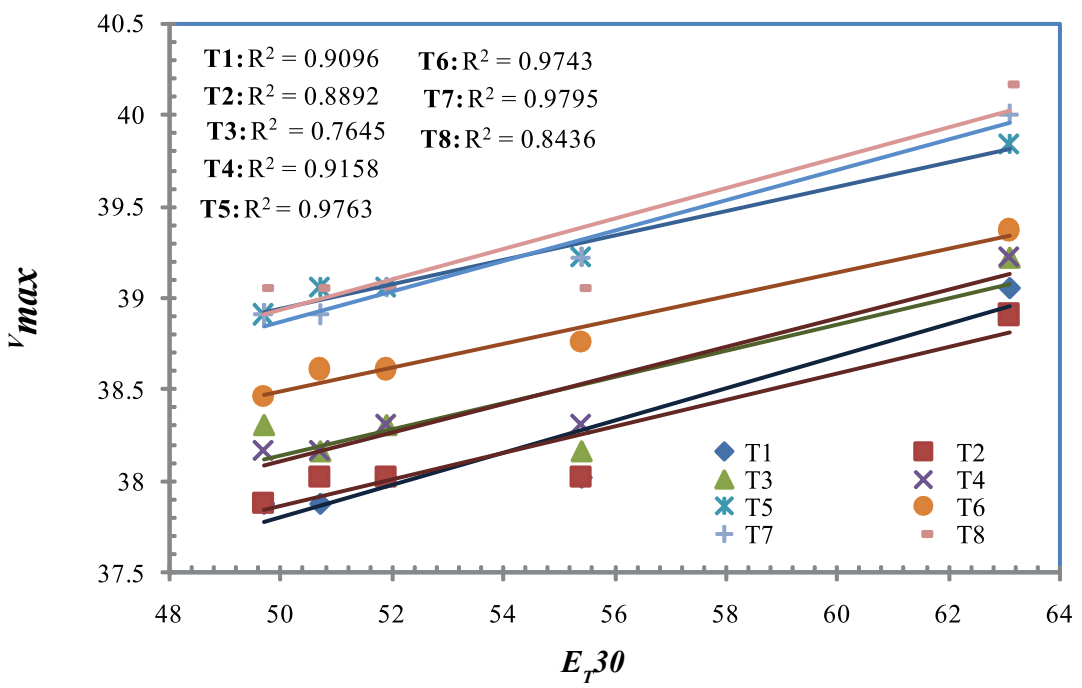

Fig. 3. Plot of absorption frequency (in $\mathrm{cm}^{-1}$ ) of T3T

Table 3

in various solvents versus the $E_{\mathrm{T}} 30$ values in protic solvents

Empirical parameters of solvent polarity

\begin{tabular}{|c|c|c|c|c|c|c|c|c|c|c|c|}
\hline \multirow[t]{2}{*}{ Solvent } & \multicolumn{8}{|c|}{$E_{\mathrm{T}}(\mathbf{T} 3 \mathbf{T})$} & \multirow{2}{*}{$f(\varepsilon, n)$} & \multirow{2}{*}{$g(n)$} & \multirow{2}{*}{$\varphi(\varepsilon, n)$} \\
\hline & $\mathbf{T 1}$ & $\mathbf{T} 2$ & T3 & T4 & T5 & T6 & $\mathbf{T 7}$ & T8 & & & \\
\hline Water & 112 & 111 & 112 & 112 & 114 & 113 & 114 & 115 & 0.912 & 0.227 & 1.366 \\
\hline Methanol & 109 & 109 & 109 & 110 & 112 & 111 & 112 & 112 & 0.854 & 0.224 & 1.302 \\
\hline Ethanol & 109 & 109 & 110 & 110 & 112 & 110 & 112 & 112 & 0.812 & 0.246 & 1.305 \\
\hline Propan-1-ol & 108 & 109 & 109 & 109 & 112 & 110 & 111 & 112 & 0.779 & 0.262 & 1.304 \\
\hline Butan-1-ol & 108 & 108 & 110 & 109 & 111 & 110 & 111 & 112 & 0.750 & 0.271 & 1.293 \\
\hline Chloroform & 108 & 106 & 110 & 107 & 110 & 108 & 110 & 109 & 0.273 & 0.302 & 0.878 \\
\hline Dioxane & 108 & 109 & 108 & 107 & 110 & 109 & 109 & 109 & 0.041 & 0.287 & 0.615 \\
\hline DMF & 103 & 106 & 106 & 106 & 106 & 106 & 106 & 107 & 0.835 & 0.292 & 1.419 \\
\hline FA & 109 & 109 & 109 & 109 & 109 & 109 & 109 & 109 & 0.894 & 0.303 & 1.501 \\
\hline DMSO & 102 & 102 & 102 & 106 & 109 & 109 & 109 & 109 & 0.840 & 0.324 & 1.487 \\
\hline Acetonitrile & 110 & 107 & 107 & 107 & 110 & 109 & 110 & 110 & 0.859 & 0.234 & 1.328 \\
\hline
\end{tabular}


The absorption data of T3T in various solvent was also analyzed in terms of various polarity scales. The first method involves the transformation of $v_{\max }\left(\mathrm{cm}^{-1}\right)$ of T3T in various solvents into molar transition energies $\left\{E_{\mathrm{T}}(\mathrm{T} 3 \mathrm{~T}), \mathrm{kcal} / \mathrm{mol}\right\}$ by using the relationship (2), [14] (Table 3):

$$
E_{\mathrm{T}}=28.591 \cdot v_{\max }
$$

The $E_{\mathrm{T}}(\mathbf{T 3 T})$ values signify transition energy which also reflects the stabilization of the triazole molecule in its ground state in a given solvent. This may be due to either hydrogen bond formation or T3T-solvent interaction. Therefore, $E_{\mathrm{T}}(\mathbf{T} 3 \mathrm{~T})$ provides a direct empirical measure of triazoline-3-thione solvation behaviour.

The spectral band shifts were also related to solvent parameter $\phi(\varepsilon, n)$ which is given as follows eq. $3,[15]$ :

$$
\phi(\varepsilon, n)=f(\varepsilon, n)+2 \cdot g(n)
$$

The function takes into account two important properties of the solvents namely the dielectric constant and the refractive index and is a sum of two independent terms namely $f(\varepsilon, n)$ and $g(n)$ which are given as follows:

$$
\begin{gathered}
f(\varepsilon, n)=\frac{2 n^{2}+1}{n^{2}+2}\left(\frac{\varepsilon-1}{\varepsilon+2}-\frac{n^{2}-1}{n^{2}+2}\right) \\
g(n)=\frac{3}{2} \frac{n^{4}-1}{\left(n^{2}+2\right)^{2}}
\end{gathered}
$$

where $\varepsilon$ is the dielectric constant and $n$ is the refractive index and both these quantities reflect the freedom of motion of electrons in the solvent and the dipole moment of the molecules. Specific solvent effects occur by interactions of the solvent and the chromophores. Figure 4 shows the trend when the spectral position $\left(v_{\max }\right)$ of the T3T in protic solvents were plotted against the solvent polarity parameter $\phi(\varepsilon, n)$.

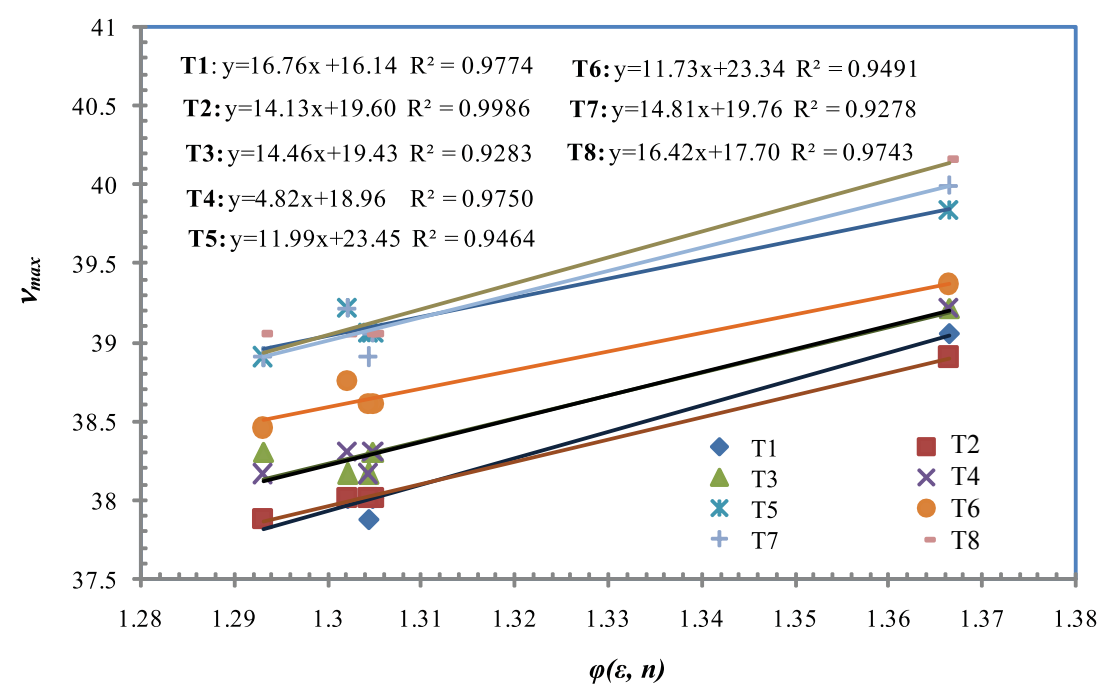

Fig. 4. Plot of absorption frequence (in $\mathrm{cm}^{-1}$ ) of T3T in protic solvents versus the $\varphi(\varepsilon, n)$ values

\subsection{LSER correlation analysis}

The analysis of solvent effect on spectral properties of T3T solutions were carried out by using the spectral position in above mentioned solvents and correlating these with the KamletTaft solvent properties namely, $\pi^{*}, \alpha, \beta, n$ and $\varepsilon$, obtained from the literature [14] and presented in Table 1. Since the shift in $v_{\max }$ values with solvent type reflects triazole-molecule interactions, an attempt was made to study this phenomenon in detail. Table 1 shows the essential solvent parameters required in this study along with the absorption frequencies for each triazoline-3-thione in these solvents (Table 2). 
Statistical evaluation of correlation models obtained using the absorption frequencies of the lower energy bands and eq. (1) showed unsatisfactory results. According the values for $\mathrm{R}<0.2$ and $\mathrm{SD}>1$ it is obviously that poor correlation models were obtained. Due to this finding, we did not take into consideration those models. This probably can be explained by ability of those compounds to exist in thione-thiol tautomeric form, although our chemical and spectral investigations showed that the thione structure dominates $[1,10]$.

Taking into consideration the fact that protic and aprotic solvents have different solvations and specific interactions with T3T, due to their polarity and hydrogen bonding, we divided the spectralsolvent correlation into two groups (protic/aprotic).

Three-correlation models (Models 1-16) were developed using experimental obtained ab- sorption frequencies for higher energy bands and $\alpha, \beta$ and $\pi^{*}$ solvatochromic parameters. The discussion was based on the quantitative values and the sign of the coefficients in the corresponding models, and the comparison of these coefficients among themselves.

Protic solvents. According the values of $s$, $b$ and $a$, in models $1-8$, the solvent effects on the absorption spectra of T3T in protic solvents, generally include important contribution from the classical solvent effect (represent by the higher positive value of the coefficient $s$ ), when the phenyl group is in position 4 (T1-T4) (Table 4). Judging from the coefficient values, generally the HBD (hydrogen bond donor) effect dominates in compound with $n$-butyl group in position 4 (T5-T7), contrary to the T8, where the classical solvent effect dominate (higher value of $s$ ).<smiles>[R]c1cccc(-c2n[nH]c(=S)n2C)c1</smiles>

(a)<smiles>[R]c1cccc(-c2n[nH]c([Se])[n+]2C)c1</smiles>

(b)

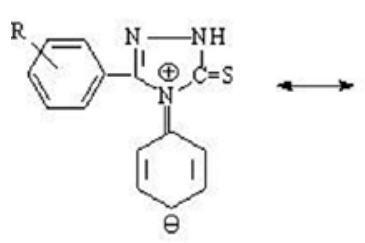

(b)

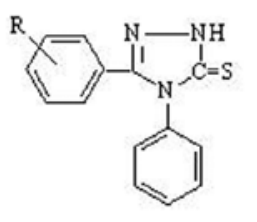

(a)

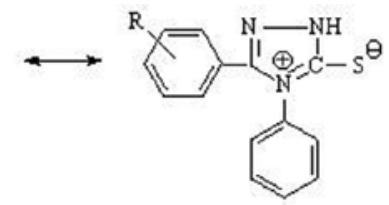

(b)

Fig. 5. Resonance structures of T3T: (a) ground state, (b) transition state

Ta ble 4

Correlation of electronic spectral data with Kamlet-Taft solvatochromic parameters for protic solvents

\begin{tabular}{|c|c|c|c|c|c|c|c|c|}
\hline No & Model & $R^{2}$ & SD & $F$ & $n$ & $s(\%)$ & $b(\%)$ & $a(\%)$ \\
\hline 1 & T1: $v_{\max }=37.43 \pm 0.05+\mathbf{2 . 9 8} \pm 0.07 \pi *+0.19 \pm 0.01 \beta-1.42 \pm 0.10 \alpha$ & 1.00 & 0.01 & 8258.60 & 5 & 64.92 & 4.14 & 30.94 \\
\hline 2 & T2: $v_{\max }=37.79 \pm 0.11+\mathbf{2 . 5 0} \pm 0.17 \pi^{*}+0.01 \pm 0.03 \beta-1.37 \pm 0.25 \alpha$ & 0.99 & 0.01 & 1046.75 & 5 & 64.43 & 0.26 & 35.31 \\
\hline 3 & T3: $v_{\max }=38.94 \pm 0.58+\mathbf{4 . 3 8} \pm 0.86 \pi^{*}+0.40 \pm 0.14 \beta-3.91 \pm 1.28 \alpha$ & 0.99 & 0.07 & 45.27 & 5 & 50.40 & 4.61 & 44.99 \\
\hline 4 & T4: $v_{\max }=37.71 \pm 0.13+\mathbf{2 . 5 5} \pm 0.20 \pi *+0.17 \pm 0.03 \beta-1.11 \pm 0.29 \alpha$ & 0.99 & 0.02 & 855.53 & 5 & 66.58 & 4.44 & 28.98 \\
\hline 5 & T5: $v_{\max }=37.77 \pm 0.26+0.52 \pm 0.38 \pi^{*}-0.13 \pm 0.06 \beta+\mathbf{1 . 3 1} \pm 0.56 \alpha$ & 0.99 & 0.03 & 159.06 & 5 & 26.53 & 6.63 & 66.84 \\
\hline 6 & T6: $v_{\max }=37.38 \pm 0.27+0.55 \pm 0.40 \pi^{*}-0.13 \pm 0.06 \beta+\mathbf{1 . 2 1} \pm 0.59 \alpha$ & 0.99 & 0.03 & 138.40 & 5 & 29.10 & 6.88 & 64.02 \\
\hline 7 & T7: $v_{\max }=37.39 \pm 0.19+1.03 \pm 0.28 \pi *+0.06 \pm 0.04 \beta+\mathbf{1 . 2 6} \pm 0.41 \alpha$ & 0.99 & 0.02 & 468.15 & 5 & 43.83 & 2.55 & 53.62 \\
\hline 8 & T8: $v_{\max }=39.18 \pm 0.72+\mathbf{3 . 6 4} \pm 1.07 \pi *+0.17 \pm 0.17 \beta-2.59 \pm 1.58 \alpha$ & 0.99 & 0.09 & 35.93 & 5 & 56.88 & 2.66 & 40.46 \\
\hline
\end{tabular}

$n$ - number of solvents; $R$ - correlation coefficient; $\mathrm{SD}$ - standard deviation; $F-F$-test 
In all cases (T1-T8) the influence of the $\beta$ term can be ignored, because of the smaller value of the coefficient $b$. The percentage contribution of the calculated solvatohromic parameters also confirm those conclusions. For compounds (T1-T4), the positive values of $s$ and $b$ indicated better stabilisation of the ground state by the classical solvent and HBA effects (Figure 5a). The HBD ( $a$ ) effects work in the opposite direction to the other solvent effects, indicating better stabilization of the transition state by the HBD solvent effects (Figure 5b). Ground state of the compounds with $n$-butyl group (T5-T8) is stabilized by classical solvent (positive values of $s$ and $a$ ). In case of $\mathbf{T} 7$ all three effects (classical solvation effect, HBA and HBD), have the positive sign, i.e. they act in same direction by stabilizing the ground state. The correlation coefficient $(\mathrm{R})$ has satisfactory values in all cases ( $R=1.00-0.99)$ (Table 4).

Aprotic solvents. In case of aprotic solvents, the models 9-16 shows that the dominant solvent effect in all T3T is HBA (represented by the higher negative values of the coefficient (b) (Table 5). Those negative values can be explained, most likely, by the ability of aprotic solvents to create an intermolecular hydrogen bond in the electronic transited stated of T3T (Figure $5 \mathrm{~b}$ ), where they act as proton acceptor (type B). The HBD effects act in same way as HBA effects (negative sign of coefficient $a$ ). For the investigated compounds (T1-T8), the negative sign of coefficients $b$ and $a$, indicates batochromic shifts with increasing solvent hydrogen-bond acceptor basicity and solvent hydrogen-bond donor acidity. This suggests stabilization of the transition state (Figure 5a) relative to the ground state (Figure $5 b$ ). The positive sign of the coefficient $s$ indicate hypsocromic shifts with increasing solvent dipolarity/polarizability of solvent.

This suggests stabilization of the ground state (Figure 5a) relative to the transition state (Figure 5b). The percentage contribution of the calculate solvatohromic parameters: $b, a$ and $s$ also confirm those conclusions. Satisfactory values for $R(0.81-0.99)$ and SD (0.02-0.64) were obtained in all cases (Table 5).

\section{T a b l e 5}

Correlation of electronic spectral data with Kamlet-Taft solvatochromic parameters for aprotic solvents

\begin{tabular}{|c|c|c|c|c|c|c|c|c|}
\hline No & Model & $R^{2}$ & SD & $F$ & $n$ & $s(\%)$ & & $a(\%)$ \\
\hline 9 & T1: $v_{\max }=38.41 \pm 1.11+13.26 \pm 7.21 \pi^{*}-\mathbf{2 1 . 4 4} \pm 9.02 \beta-18.45 \pm 8.91 \alpha$ & 0.92 & & & 6 & & & \\
\hline 10 & $\mathbf{T 2}: v_{\max }=37.54 \pm 1.34+14.73 \pm 8.68 \pi^{*}-\mathbf{2 1 . 6 1} \pm 10.86 \beta-19.71 \pm 10.72 \alpha$ & 0.81 & 0.64 & 2.79 & 6 & 26.28 & & 35.17 \\
\hline 11 & T3: $v_{\max }=39.05 \pm 0.68+8.73 \pm 5.95 \pi^{*}-\mathbf{1 5 . 7 5} \pm 7.57 \beta \beta-13.09 \pm 7.48 \alpha$ & 0.98 & 0.31 & 16.21 & 6 & 23.24 & 41.92 & 34.84 \\
\hline 12 & T4: $v_{\max }=37.29 \pm 0.46+5.02 \pm 3.00 \pi^{*}-\mathbf{7 . 1 9} \pm 3.56 \beta-5.97 \pm 3.71 \alpha$ & 0.88 & 0.22 & 5.03 & 6 & & & 2.84 \\
\hline 13 & T5: $v_{\max }=39.17 \pm 0.04+6.49 \pm 0.36 \pi^{*}-\mathbf{1 2 . 0 3} \pm 0.50 \beta-10.51 \pm 0.48 \alpha$ & 0.99 & 0.02 & 623.36 & 6 & 22.37 & 41.43 & 36.20 \\
\hline 14 & T6: $v_{\max }=38.49 \pm 0.39+9.71 \pm 3.31 \pi^{*}-\mathbf{1 5 . 6 2} \pm 4.61 \beta-14.03 \pm 4.36 \alpha$ & 0.95 & 0.18 & 6.52 & 5 & 24.67 & 39.68 & 35.65 \\
\hline 15 & T7: $v_{\max }=39.08 \pm 0.28+9.23 \pm 2.37 \pi^{*}-\mathbf{1 5 . 9 5} \pm 3.30 \beta-14.04 \pm 3.12 \alpha$ & 0.98 & 0.13 & 19.46 & 5 & 23.53 & 40.67 & 35.80 \\
\hline 16 & T8: $v_{\max }=38.79 \pm 0.21+9.59 \pm 1.73 \pi^{*}-\mathbf{1 5 . 7 7} \pm 2.41 \beta-14.14 \pm 2.28 \alpha$ & 0.99 & 0.09 & 26.63 & 5 & 24.28 & 39.92 & 35.80 \\
\hline
\end{tabular}

$n$ - number of solvents; $R$ - correlation coefficient; $\mathrm{SD}$ - standard deviation; $F-F$-test

An attempt was made for evaluation of correlation models obtained using the absorption frequencies in all 11 solvents, but unsatisfactory results were obtained. According to the values for $R(0.55 \div 0.85)$ and $\mathrm{SD}(0.29 \div 0.72)$, it is obvious that poor correlation models were obtained. Due to this finding, we did not take into consideration those models.

Validation. We have also undertaken a cross-validation methodology for choosing 
predictive power of the proposed models 1-16 for all compounds (T1-T8). The mentioned methodology is essential because a model with good statistics may not have good predictive potential. Thus, the various cross-validation parameters calculated for the proposed models are presented in Table 6 and are discussed below.

To test the quality of the regression models, beside basic parameters $R, \mathrm{SD}$ and $F$-test, the additional statistical parameters were also used such as PRESS (Predictive residual error Sum of Squares $)=\Sigma\left(Y_{\text {pred }}-Y_{\text {exp }}\right)^{2}$; SSY (Sum of squares of deviation of the experimental values from their mean $)=\Sigma\left(Y_{\text {exp }}-Y_{\text {mean }}\right)^{2}$, where $Y_{\text {pred }}$ predicted, $Y_{\text {exp }}$ - experimental and $Y_{\text {mean }}$ - mean values of the target properties $v_{\max }$, respectively, and $Q^{2}$ - Cross-validation squared correlation coefficient $\left(Q^{2}=1-\mathrm{PRESS} / \mathrm{SSY}\right)$.

Although the basic statistical parameters $R$ and SD, showed satisfactory values, good cross-validation $Q^{2}$ values and PRESS appears to be important statistical parameters accounting for a good estimate of the real predictive error of the model. PRESS value less than SSY indicate that the model predicts better than chance and can be considered statistically significant. For a reasonable model, $Q^{2}$ should be $>0.72$ and PRESS/SSY should be smaller than 0.4 .

Next step in our work was extending the statistical evaluation of models $1-16$. Based on the values of $Q^{2}(0.1-0.5)$ and PRESS/SSY $(0.6-1.1)$, it has been confirmed that models 9-16 were not statistically significant and they are not discussed in this paper. Hence, further discussion is focused on the statistical power of models $1-8$.

In our case, for models proposed for protic solvents (models $1-8), Q^{2}$ values $(>0.97)$ and PRESS/SSY values $(<0.0260)$, indicating that those models are significant are useful tool for predicting solvent effects on the ultraviolet absorption spectra of T3T.

In order to confirm our solvatochromic findings, $v_{\max }$ values calculated by corresponding Kamlet-Taft model $\left(v_{\text {model }}\right)$ are compared

T a b 1 e 6

Quality of models 1-8 for protic solvents by means of $Q^{2}$, PRESS and PRESS/SSY and predictive correlation coefficient $\left(R_{\text {pre }}\right)$

\begin{tabular}{|c|c|c|c|c|}
\hline Model & $Q^{2}$ & PRESS & PRESS/SSY & $R_{\text {pre }}$ \\
\hline 1 & 1.0000 & 0.0000 & 0.0000 & $\begin{array}{c}v_{\max } \mathrm{ob} .=1.0000 v_{\max } \mathrm{cal} .+0.0014 \\
R_{\mathrm{pre}}{ }^{2}=1.0000\end{array}$ \\
\hline 2 & 0.9997 & 0.0002 & 0.0030 & $\begin{array}{c}v_{\max } \mathrm{ob} .=0.9996 v_{\max } \mathrm{cal} .+0.0149 \\
R_{\text {pre }}^{2}=0.9996\end{array}$ \\
\hline 3 & 0.9736 & 0.0200 & 0.0260 & $\begin{array}{c}v_{\max } \mathrm{ob} .=1.0240 \quad v_{\max } \mathrm{cal} .-0.9635 \\
R_{\mathrm{pre}}^{2}=0.9838\end{array}$ \\
\hline 4 & 0.9994 & 0.0004 & 0.0263 & $\begin{array}{c}v_{\max } \text { ob. }=0.9996 \quad v_{\max } \text { cal. }+0.0149 \\
R_{\mathrm{pre}}{ }^{2}=0.9996\end{array}$ \\
\hline 5 & 0.9995 & 0.0004 & 0.0005 & $\begin{array}{c}v_{\max } \mathrm{ob} .=0.9979 v_{\max } \mathrm{cal} .+0.0818 \\
R_{\mathrm{pre}}^{2}=0.9979\end{array}$ \\
\hline 6 & 0.9974 & 0.0013 & 0.0026 & $\begin{array}{c}v_{\max } \mathrm{ob} .=0.9975 v_{\max } \mathrm{cal} .+0.0963 \\
R_{\text {pre }}^{2}=0.9976\end{array}$ \\
\hline 7 & 0.9990 & 0.0008 & 0.0010 & $\begin{array}{c}v_{\max } \mathrm{ob} .=0.9993 \quad v_{\max } \mathrm{cal} .+0.0284 \\
R_{\mathrm{pre}}^{2}=0.9993\end{array}$ \\
\hline 8 & 0.9911 & 0.0086 & 0.0089 & $\begin{array}{c}v_{\max } \mathrm{ob} .=0.9908 \quad v_{\max } \mathrm{cal} .+0.3607 \\
R_{\mathrm{pre}}{ }^{2}=0.9908\end{array}$ \\
\hline
\end{tabular}




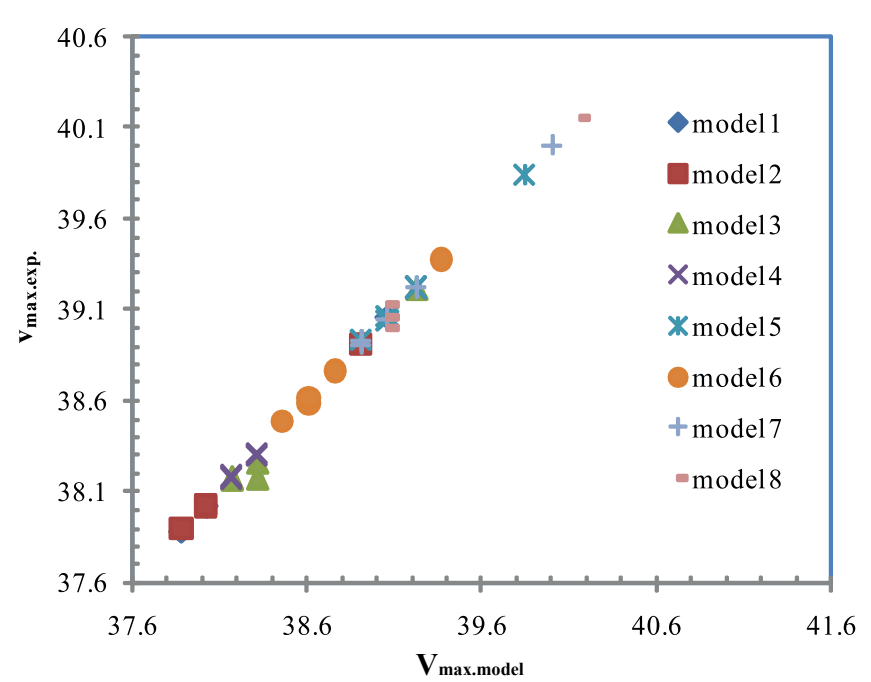

Fig. 6. Values of $v_{\max (\text { exp. })}$ and $v_{\max (\text { model })}$ for models $1-8$

with those $v_{\max }$ values experimental obtained $\left(v_{\exp }.\right)$. Within the range of acceptable experimental error, the values agree well, for protic solvents only. From the plot, constructed between the experimental and calculated $v_{\max }$ values (Figure 6) we have calculated predictive correlation coefficient $\left(R_{\mathrm{pre}}\right)$, (Table 6). Once again, the obtained predictive correlation coefficient, confirmed our findings for protic solvents $\left(R_{\text {pre }}=0.98-1.00\right)$.

\section{CONCLUSIONS}

The effects of solvent polarity and hydrogen bonding on the UV absorption spectra of 4,5-disubstituted-1,2,4-triazoline-3-thiones were interpreted by means of linear solvation energy relationship by implementation of Kamlet-Taft concepts. Correlation models obtained using the absorption frequencies of the lower energy bands, according the values for basic statistical parameters $R$ and SD, showed unsatisfactory results.

Three-correlation models were developed using experimental obtained absorption frequencies for the highest absorption band with the solvatochromic parameters: $\pi^{*}, \alpha$ and $\beta$.

Statistical evaluation of obtained models demonstrated that models only for protic sol- vents can be used accurately to evaluate the solvent effects. The result show that the solvent effect on UV absorption spectra of investigated T3T is very complex and strongly dependent on the nature of the substituent in position 4 (phenyl or $n$-butyl group) and in position 5 (2-, 3- or 4-substitutes phenyl moiety).

Since, this is the first report of the solvatochromism studies on complex system such as triazoline-3-thione, we expect that the obtained results will draw attention towards similar investigations of the biological active 4,5-disubstituted-1,2,4-triazoline-3-thiones.

\section{REFERENCES}

[1] M. Lazarević, V. Dimova, J. Csanadi, M. Popsavin, Lj. Klisarova, Synthesis of some new 4,5-disubstituted-2,4-dihidro-3H-1,2,4-triazoline-3-thiones, Bull. Chem. Technol. Macedonia 16 (1997), 97103.

[2] N. Perisic-Janjic, M. Acinski, N. Janjic, M. Lazarevic, V. Dimova, Study of the lipophilicity of some 1,2,4-triazole derivatives by RPHPLC and TLC, Journal of Planar Chromatography 13 (2000), 281-284.

[3] M. Lazarevic, V. Dimova, D. Molnar Gabor, V. Kakurinov, K. Colanceska, Synthesis of some N1aryl/heteroarylaminomethyl/ethyl-1,2,4-triazoles and their antibacterial and antifungal activities, Heterocyclic Communications 7 (2001), 577-582.

[4] K. Colanceska, V. Dimova, V. Kakurinov, D. Molnar-Gabor, A. Buzarovska, Synthesis and antibacterial and antifungal activity of 4-substituted-5aryl-1,2,4-triazole, Molecules 6 (2001), 815-824.

[5] V. Dimova, K. Colanceska Ragenovic, V. Kakurinov, $N^{1}$-aryl/heteroarylaminometil/ethyl-1,2,4-triazoles, Part II: Antimicrobial activity against Bacillus subtilis, Int. J. Mol. Sci. 7 (2006), 119-129.

[6] V. Dimova, N. Perišić-Janjić, QSAR study by 1,2,4-triazoles using several physicochemical descriptors, Maced. J. Chem. Chem. Eng. 28 (2009), 79-89.

[7] V. Daniloska, J. Blazevska-Gilev, V. Dimova, R. Fajgar, R. Tomovska, UV light induced surface modification of hdpe films with bioactive compounds, Applied Surface Science 256 (2010), 2276-2283. 
[8] V. Dimova, A study of behaviour of some 5-substituted-4-phenyl-1,2,4-triazoline-3-thiones in sulfuric acid solution using characteristic vector analysis, Turk J Chem. 35 (2011), 109-120.

[9] D. H. Purohit, B. L. Dodiya, R. M. Ghetiya, P. B. Vekariya, H. S. Joshi, Synthesis and Antimicrobial Activity of Some New 1,3,4-Thiadiazoles and 1,3,4-Thiadiazines Containing 1,2,4-Triazolo Nucleus, Acta Chim. Slov. 58 (2011), 53-59.

[10] M. Pitucha, B. Polak, M. Swatko-Ossor, Ł. Popiołek, G. Ginalskac, Determination of the lipophilicity of some new derivatives of thiosemicarbazide and 1,2,4-triazoline-5-thione with potential antituberculosis activity, Croat. Chem. Acta 83 (2010), 299-306.

[11] C. Öğretir, Y. Gülseven Sidir, İ. Sider, E. Taşal, Quantum chemical studies on tautomerism and basicity behavior of some 1,2,4-triazole derivatives, Turk J Chem. 34 (2010), 977-988.

[12] U. Karakuş, B. Çoruh, E. Barlas-Durgun, M. Vázquez-López, S. Özbaş-Turan, J. Akbuğa1, S. Rollas, Synthesis and cytotoxic activity of some 1,2,4-triazoline-3-thione and 2,5-disubstituted1,3,4-thiadiazole derivatives, Marmara Pharm. J. 14 (2010), 84-90.

[13] K. Parmar, B. Suthar, S. Prajapati, A. Suthar, Synthesis and biological activity of novel 1,3,5-trisubstituted 1,2,4-triazole derivatives, J. Heterocycl. Chem. 47 (2010), 156-161.

[14] C. Reichardt, Solvents and Solvent Effects in Organic Chemistry, Wiley-VCH, Weinheim, 2004.

[15] C. Reichardt, Solvatochromic Dyes as Solvent Polarity Indicators, Chem Rev. 94 (1994), 23192358.

[16] J. M. Kamlet, J. L. Abboud, R. W. Taft, The solvatochromic comparison metod. The $\pi^{*}$ scale of solvent solarities, J Am Chem Soc. 99 (1977), 6027-6038.
[17] J. M. Kamlet, J. L. Abboud, M. H. Abraham, R. W. Taft, Linear solvation energy relationships. A comprehensive collection of the solvatochromic parameters, $\pi^{*}, \alpha, \beta$ and some methods for simplifying the generalized solvatochromic equation, $J$ Org Chem. 48 (1983), 2877-2887.

[18] Y. Marcus, The properties of organic liquids that are relevant to their use as solvating solvents, Chem Soc Rev. 22 (1993), 409-416.

[19] A. Kawski. On the Estimation of Excited-State Dipole Moments from Solvatochromic Shifts of Absorption and Fluorescence Spectra, Z. Naturforsch, A: Phys Sci. 57A (2002), 255-262.

[20] M. Jabbari, F. Gharib, Solvent Effects on Protonation Equilibria of Some Amino Acids and Peptides in Different Aqueous Solutions of Ethanol, Acta Chim. Slov. 57 (2010), 325-331.

[21] A. Oehlke, K. Hofmann, S. Spange, New aspects on polarity of 1-alkyl-3-methylimidazolium salts as measured by solvatochromic probes, New J. Chem. 30 (2006), 533-536.

[22] N. D. Divjak, N. R. Banjac, N. V. Valentić, G.S. Ušćumlić, Synthesis, structure and solvatochromism of 5-methyl-5-(3- or 4-substituted phenyl)hydantoins, J. Serb. Chem. Soc. 74 (2009), 1195-1205.

[23] G. S. Ušćumlić, J. B. Nikolić, The study of linear solvation energy relationship for the reactivity of carboxylic acids with diazodiphenylmethane in protic and aprotic solvents, J. Serb. Chem. Soc. 74 (2009), 1335-1357.

[24] M. R. Hadjmohammadi, M. J. Chaichi, M. Yousefpour, Solvatochromism Effect of Different Solvents on UV-Vis Spectra of Flouresceine and its Derivatives, Iran. J. Chem. Chem. Eng. 27 (2008), 9-14. 